TITLE:

\title{
Temperature and injection level dependencies and impact of thermal oxidation on carrier lifetimes in p-type and n-type $4 \mathrm{H}$ - SiC epilayers
}

\section{$\operatorname{AUTHOR(S):~}$}

Hayashi, T.; Asano, K.; Suda, J.; Kimoto, T.

\section{CITATION:}

Hayashi, T....[et al]. Temperature and injection level dependencies and impact of thermal oxidation on carrier lifetimes in p-type and n-type 4H-SiC epilayers. JOURNAL OF APPLIED PHYSICS 2011, 109(1): 014505.

\section{ISSUE DATE:}

2011-01-01

URL:

http://hdl.handle.net/2433/160641

\section{RIGHT:}

Copyright 2011 American Institute of Physics. This article may be downloaded for personal use only. Any other use requires prior permission of the author and the American Institute of Physics. The following article appeared in JOURNAL OF APPLIED PHYSICS 109, 014505 (2011) and may be found at http://link.aip.org/link/?jap/109/014505 


\section{AIP $\mid$ Appolied Physics}

\section{Temperature and injection level dependencies and impact of thermal oxidation on carrier lifetimes in p-type and n-type 4H-SiC epilayers}

T. Hayashi, K. Asano, J. Suda, and T. Kimoto

Citation: J. Appl. Phys. 109, 014505 (2011); doi: 10.1063/1.3524266

View online: http://dx.doi.org/10.1063/1.3524266

View Table of Contents: http://jap.aip.org/resource/1/JAPIAU/v109/i1

Published by the American Institute of Physics.

\section{Related Articles}

Local conductivity and the role of vacancies around twin walls of (001)-BiFeO3 thin films

J. Appl. Phys. 112, 052003 (2012)

Role of Ti phases in the modulation of border traps at the TiO2/n-Si interfaces

J. Appl. Phys. 112, 044513 (2012)

Effect of residual impurities on transport properties of $\beta$-FeSi2 epitaxial films grown by molecular beam epitaxy J. Appl. Phys. 112, 013702 (2012)

Temperature dependent conductivity of polycrystalline Cu2ZnSnS4 thin films

Appl. Phys. Lett. 100, 263903 (2012)

Reduced leakage currents and possible charge carriers tuning in Mg-doped $\mathrm{Ga} 0.6 \mathrm{Fe} 1.4 \mathrm{O} 3$ thin films Appl. Phys. Lett. 100, 262904 (2012)

\section{Additional information on J. Appl. Phys.}

Journal Homepage: http://jap.aip.org/

Journal Information: http://jap.aip.org/about/about_the_journal

Top downloads: http://jap.aip.org/features/most_downloaded

Information for Authors: http://jap.aip.org/authors

\section{ADVERTISEMENT}

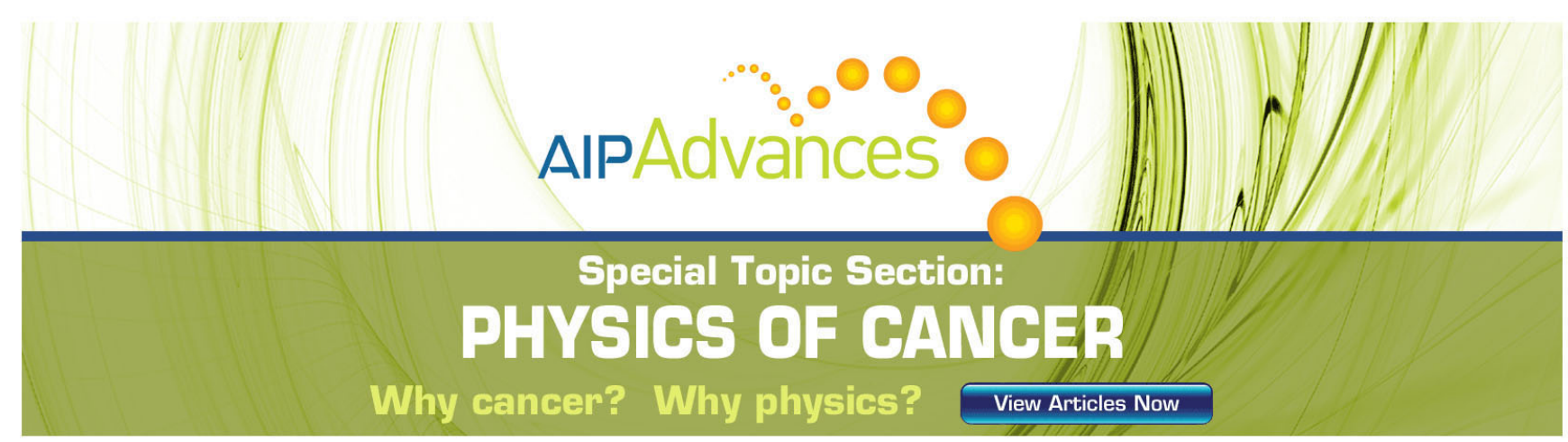




\title{
Temperature and injection level dependencies and impact of thermal oxidation on carrier lifetimes in p-type and n-type $4 \mathrm{H}-\mathrm{SiC}$ epilayers
}

\author{
T. Hayashi, ${ }^{1,2, a)}$ K. Asano, ${ }^{2}$ J. Suda, ${ }^{1}$ and T. Kimoto ${ }^{1}$ \\ ${ }^{1}$ Department of Electronic Science and Engineering, Kyoto University, Kyotodaigaku-katsura, Nishikyo, \\ Kyoto 615-8510, Japan \\ ${ }_{2}^{2}$ Power Engineering R\&D Center, Kansai Electric Power Co., Inc. 3-11-20 Nakoji, Amagasaki 661-0974, \\ Japan
}

(Received 14 July 2010; accepted 1 November 2010; published online 11 January 2011)

\begin{abstract}
Dependencies of temperature and injection level on carrier lifetimes in $50 \mu \mathrm{m}$ thick p-type and n-type $4 \mathrm{H}-\mathrm{SiC}$ epilayers have been investigated. The carrier lifetimes have been measured by differential microwave photoconductance decay measurements at various injection levels and temperatures. In both p-type and n-type epilayers, the carrier lifetimes gradually increased with increasing the injection level, which were naturally expected from the Shockley-Read-Hall (SRH) model, and after taking a maximum, the lifetimes dropped at the very high-injection level. In contrast, the carrier lifetimes exhibited continuous increase with elevating the temperature for both epilayers. In addition, the impact of thermal oxidation process on the carrier lifetimes has been also investigated. The thermal oxidation process, by which the $\mathrm{Z}_{1 / 2}$ and $\mathrm{EH}_{6 / 7}$ centers were remarkably reduced that had been observed in $\mathrm{n}$-type $4 \mathrm{H}-\mathrm{SiC}$ in our previous work, led to the improvement of the carrier lifetimes especially for n-type epilayers. The carrier lifetime reached $4.1 \mu \mathrm{s}$ in p-type and $6.1 \mu \mathrm{s}$ in n-type epilayers at $250{ }^{\circ} \mathrm{C}$ with an injection level of $1.8 \times 10^{16} \mathrm{~cm}^{-3}$ through the thermal oxidation processing. (C) 2011 American Institute of Physics. [doi:10.1063/1.3524266]
\end{abstract}

\section{INTRODUCTION}

Owing to the wide band gap, the high breakdown field and high thermal conductivity, silicon carbide $(\mathrm{SiC})$ is promising as a semiconductor material for high-power, hightemperature, and high-frequency devices. ${ }^{1,2}$ In recent years, the real applications of $\mathrm{SiC}$ power devices have started through the progress of the bulk and epitaxial growth technology and development of the device process technology. ${ }^{2,3}$ As for very high-voltage $(>5 \mathrm{kV})$ and high-current power semiconductor devices applied for large electric power conversion systems, bipolar devices are more desirable than the unipolar devices because of the ability to achieve low onresistance at high-current density by the conductivity modulation. If the carrier lifetime is short, however, the conductivity modulation does not work effectively and the low onresistance cannot be attained.

In spite of the indirect band structure, the carrier lifetimes usually observed in $\mathrm{SiC}$ are still short, about $1 \mu \mathrm{s}$. At an early stage, Bergman et $a l .{ }^{4}$ have shown that the small grain boundaries strongly affect the carrier lifetimes in SiC. After the crystalline quality has been improved, however, it has turned out that there are other lifetime-killing defects besides the macro structural defects. Tawara et al. ${ }^{5}$ have shown that the $\mathrm{Z}_{1 / 2}$ and $\mathrm{EH}_{6 / 7}$ centers influence the carrier lifetimes of $4 \mathrm{H}-\mathrm{SiC}$ epilayers. Klein et al. ${ }^{6}$ have reported the relation between the inverse of carrier lifetimes and the concentration of $\mathrm{Z}_{1 / 2}$ center for $4 \mathrm{H}-\mathrm{SiC}$ epilayers (although the plotting range is rather small, within one order of magnitude). Danno et $a .^{7}$ have revealed that the relation between the carrier lifetime and the $\mathrm{Z}_{1 / 2}$ and/or $\mathrm{EH}_{6 / 7}$ centers in the

${ }^{a)}$ Electronic mail: hayashi@semicon.kuee.kyoto-u.ac.jp. wide range of the trap concentration and clarify that the carrier lifetimes are limited by the $\mathrm{Z}_{1 / 2}$ and/or $\mathrm{EH}_{6 / 7}$ centers. They also clarified that the carrier lifetimes were limited by other factors such as surface recombination if the $\mathrm{Z}_{1 / 2}$ concentration was low enough. Klein et al. ${ }^{6}$ and Reshanov et al. ${ }^{8}$ concluded that $\mathrm{EH}_{6 / 7}$ cannot be a lifetime killer by comparing deep-level transient spectroscopy (DLTS) spectra of a pn junction with and without minority-carrier injection. More recently, reduction in these deep levels has been tried and successful improvement of the carrier lifetime has been reported. Storasta and Tsuchida ${ }^{9}$ have shown dramatic reduction in the concentration of the $\mathrm{Z}_{1 / 2}$ center by the carbon implantation combined with subsequent diffusion by hightemperature annealing. Hiyoshi and Kimoto ${ }^{10}$ have also shown the elimination of these centers by thermal oxidation.

However, these beneficial results have mainly addressed to $\mathrm{n}$-type $4 \mathrm{H}-\mathrm{SiC}$, and there have been very few reports on the carrier lifetimes in thick and lightly doped p-type $\mathrm{SiC}$, which is often employed as the voltage-blocking region of high-voltage $\mathrm{SiC}$ switching devices such as thyristors ${ }^{11}$ and insulated gate bipolar transistors (IGBTs). ${ }^{12}$ In this paper, the carrier lifetimes in both p-type and n-type thick $4 \mathrm{H}-\mathrm{SiC}$ epilayers are investigated by using differential microwave photoconductance decay $(\mu$-PCD) measurements. In particular, the authors present the dependencies of the carrier lifetimes on temperature and injection level for both types of $\mathrm{SiC} \mathrm{ep-}$ ilayers. Impacts of thermal oxidation on the carrier lifetimes are also investigated.

\section{EXPERIMENTAL}

Both p-type and n-type epitaxial layers used in this study were grown on $8^{\circ}$ off-axis $4 \mathrm{H}-\mathrm{SiC}(0001)$ substrates by 


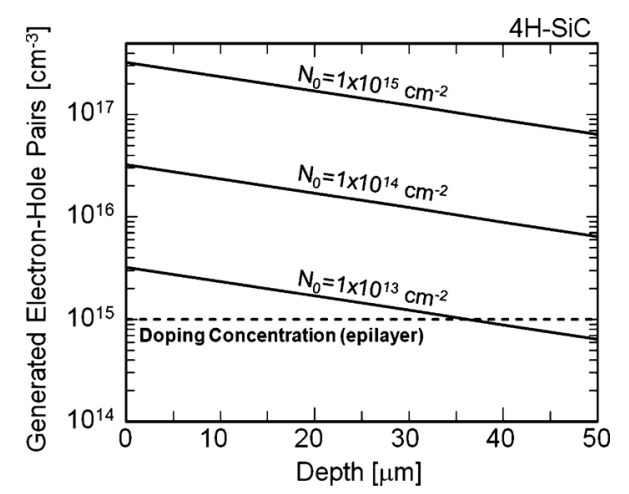

FIG. 1. Concentration of generated electron and hole pairs as a function of the depth when $4 \mathrm{H}-\mathrm{SiC}$ is illuminated with a YLF-3HG laser (wavelength: $349 \mathrm{~nm}) . \mathrm{N}_{0}$ is the density of photons irradiated onto the sample surface. The concentration was calculated by using the absorption coefficient at this wavelength $\left(\alpha=324 \mathrm{~cm}^{-1}\right){ }^{14}$

chemical vapor deposition. The thickness of epilayers is both $50 \mu \mathrm{m}$, and the doping concentration is $9.0 \times 10^{14} \mathrm{~cm}^{-3}$ for p-type, and $1.2 \times 10^{15} \mathrm{~cm}^{-3}$ for $\mathrm{n}$-type, respectively. For these epilayers, the carrier lifetimes were measured before thermal oxidation (as-grown materials) and after oxidation. For investigating the impact of thermal oxidation, the wafers were oxidized in dry $\mathrm{O}_{2}\left(10 \%\right.$ diluted in $\left.\mathrm{N}_{2}\right)$ ambient at $1300{ }^{\circ} \mathrm{C}$ for $5 \mathrm{~h}$, and after oxidation, the surface oxides were removed by hydrofluoric acid etching.

The carrier lifetimes of both $\mathrm{n}$-type and p-type $\mathrm{SiC}$ epilayers were measured by using differential $\mu$-PCD. In this measurement, the excess carriers were generated by a pulsed YLF (yttrium lithium fluoride)-3HG laser, of which wavelength was $349 \mathrm{~nm}$. Decay of electrical conductivity resulting from recombination of electron-hole pairs was monitored with reflectivity of microwave at a frequency of $26 \mathrm{GHz}$. The difference in microwave reflectivity from areas with and without laser illumination was used as $\mu$-PCD signals to increase the signal-to-noise ratio. This method has been employed as a standard technique for lifetime measurement of $\mathrm{Si}^{13}$
In order to investigate the influence of carrier injection level on the carrier lifetime, the density of photons irradiated onto the sample surface $\left(\mathrm{N}_{0}\right)$ was varied from 1 $\times 10^{12} \mathrm{~cm}^{-2}$ to $1 \times 10^{15} \mathrm{~cm}^{-2}$. Figure 1 shows the concentration of generated electron-hole pairs as a function of the depth, which was calculated by using the absorption coefficient at this wavelength $\left(\alpha=324 \mathrm{~cm}^{-1}\right){ }^{14}$ Thus the concentration of generated carriers (excitation intensity) is estimated to be from low $10^{14} \mathrm{~cm}^{-3}$ to low $10^{17} \mathrm{~cm}^{-3}$. In this figure, the doping concentration of both p-type and n-type epilayers is indicated by a dashed line. It should be noted that the free hole concentration in the p-type epilayer is about one order of magnitude lower than the acceptor concentration at room temperature because of the high activation energy of $\mathrm{Al}$ acceptors. To investigate the temperature dependence of carrier lifetime, the measurement temperature was varied from $\mathrm{RT}\left(23^{\circ} \mathrm{C}\right)$ to $250{ }^{\circ} \mathrm{C}$.

\section{RESULTS AND DISCUSSIONS}

Figure 2 shows how to determine carrier lifetimes from the measured PCD curves at various injection levels. Figure 2(a) shows the typical example of PCD curves measured for a p-type $4 \mathrm{H}-\mathrm{SiC}$ epilayer with various excitation intensities at room temperature. In this figure, all the decay curves are plotted in the absolute $\mu$-PCD signal intensity (the $\mu$-PCD signal intensity is proportional to the excess carrier concentration). Owing to the improved signal-to-noise ratio in differential $\mu$-PCD, decay curves could be acquired in the wide range of signal intensity. As clearly seen in this figure, the decay curves do not always follow a single exponential function, especially for p-type $4 \mathrm{H}-\mathrm{SiC}$. This nonexponential decay after the fast initial decay is expected from two distinct exponential components, corresponding to the high-level and low-level Shockley-Read-Hall (SRH) lifetimes. In between these two extremes, the carrier lifetimes must exhibit gradual change, depending on the energy level and capture cross sections of the SRH recombination center. Thus, the differential slopes for the decay curves were calculated at a given

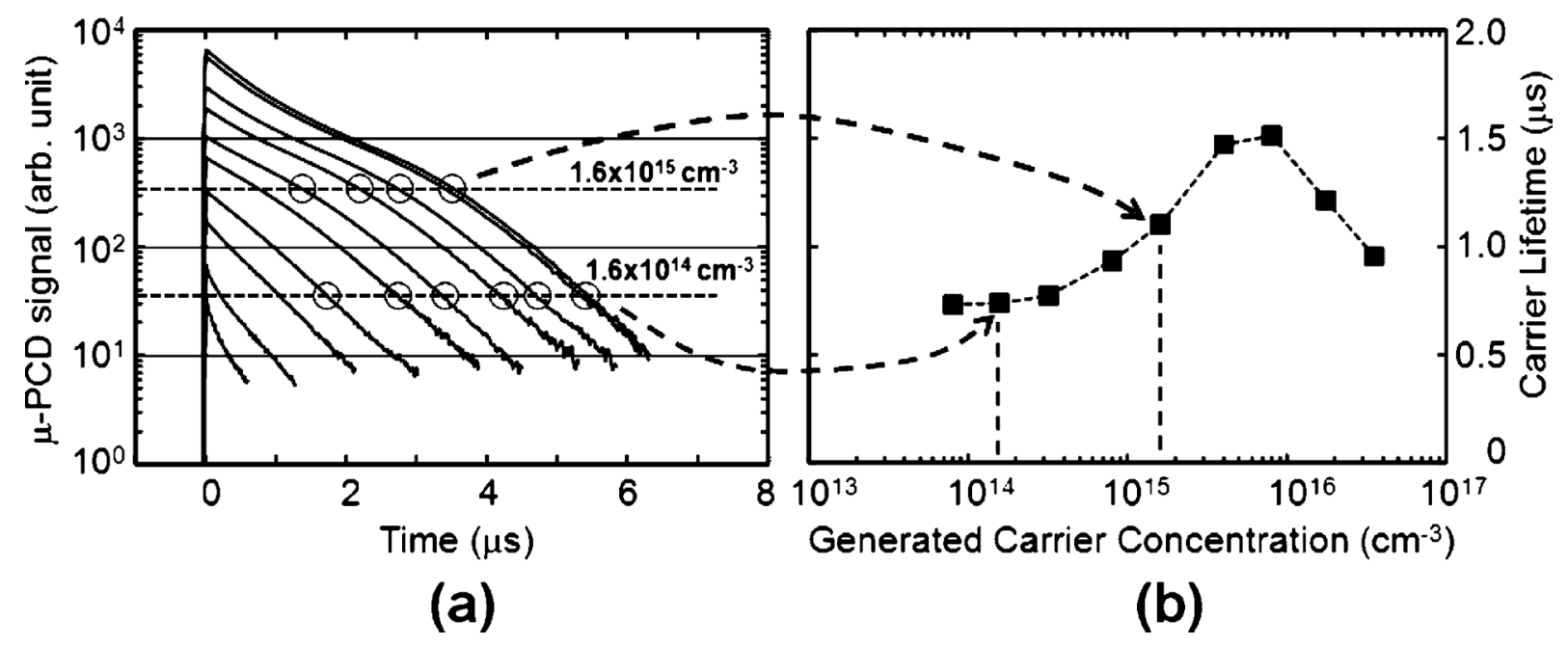

FIG. 2. (a) PCD curves measured for a $50 \mu \mathrm{m}$ thick p-type $4 \mathrm{H}-\mathrm{SiC}$ epilayer with various excitation intensities at room temperature. The excitation intensity is $1.6 \times 10^{14} \mathrm{~cm}^{-3}, \quad 3.2 \times 10^{14} \mathrm{~cm}^{-3}, \quad 8.0 \times 10^{14} \mathrm{~cm}^{-3}, \quad 1.6 \times 10^{15} \mathrm{~cm}^{-3}, \quad 4.0 \times 10^{15} \mathrm{~cm}^{-3}, \quad 8.0 \times 10^{15} \mathrm{~cm}^{-3}, \quad 1.8 \times 10^{16} \mathrm{~cm}^{-3}, \quad 3.5 \times 10^{16} \mathrm{~cm}^{-3}, \quad 8.7$ $\times 10^{16} \mathrm{~cm}^{-3}$, and $1.8 \times 10^{17} \mathrm{~cm}^{-3}$, respectively. (b) Injection level dependence of carrier lifetimes for a $50 \mu \mathrm{m}$ thick p-type $4 \mathrm{H}-\mathrm{SiC}$ epilayer at room temperature calculated from the slope of decay curves. 


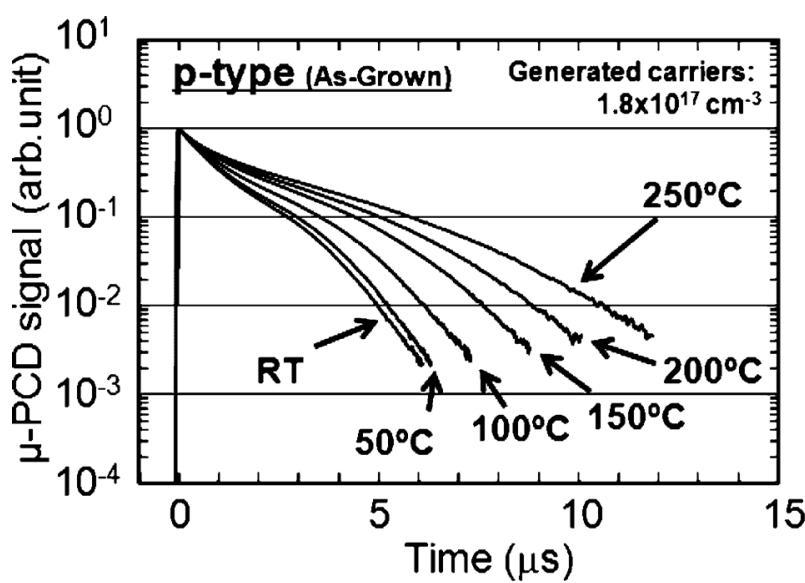

(a)

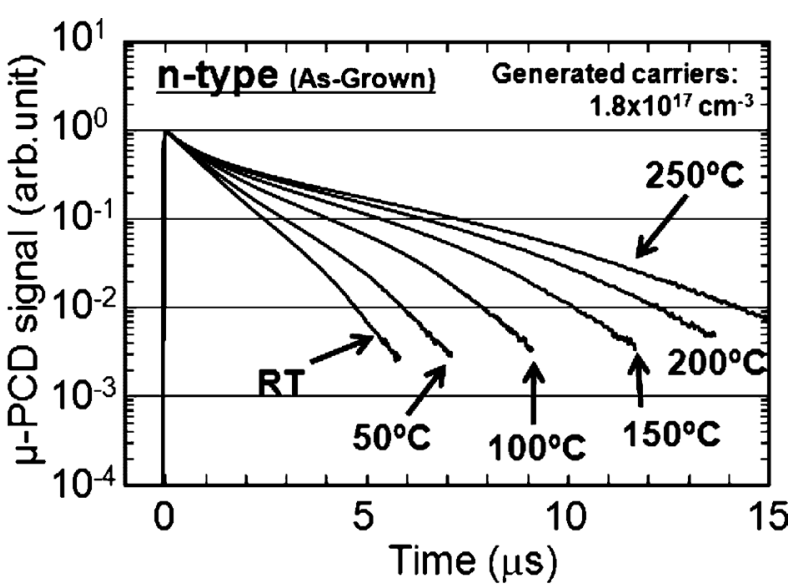

(b)

FIG. 3. PCD curves measured for $50 \mu \mathrm{m}$ thick (a) p-type and (b) n-type $4 \mathrm{H}-\mathrm{SiC}$ as-grown epilayers at various temperatures. The excitation intensity is $1.8 \times 10^{17} \mathrm{~cm}^{-3}$.

$\mu$-PCD signal intensity (corresponding to an injection level) to obtain the carrier lifetimes at a given injection level. As shown in Fig. 2(b), the carrier lifetime at each injection level was defined as the average time constant calculated at the corresponding signal intensity of two or more decay curves measured above the injection level. The peak injection level for each decay curve was determined from the peak value of the measured decay curve, taking account of the excitation intensity and the carrier distribution in Fig. 1. Thus, the injection level dependence of the carrier lifetime were obtained in this way and indicated in Fig. 2(b).

Figure 3 shows the PCD curves measured for (a) p-type and (b) n-type as-grown epilayers at various temperatures with a fixed excitation intensity $\left(1.8 \times 10^{17} \mathrm{~cm}^{-3}\right)$. The carrier lifetimes exhibited continuous increase with elevating the temperature for both epilayers. It is noted that the temperature dependence of absorption coefficients was neglected due to the lack of reliable data. In these decay curves, fast decay at the initial stage is observed, and relatively sharp drop of the $\mu$-PCD signals is also seen near the end of measurement time. Based on a simulation study of the excess carrier distribution taking account of diffusion and surface recombination, the authors speculate that the fast decay at the initial stage $(0-0.5 \mu \mathrm{s})$ may originate from severe surface and substrate recombination. ${ }^{15}$ Here, the substrate recombination includes recombination at the epilayer/substrate interface as well as recombination inside the substrate due to the very short lifetime in the substrate. In addition, at the extremely high-injection level $\left(\Delta \mathrm{n}>10^{17} \mathrm{~cm}^{-3}\right)$, the carrier lifetime limited by the radiative recombination and Auger recombination can be estimated to be about $3 \mu$ s and $30 \mu \mathrm{s}$, respectively. Thus, the initial fast decay must be significantly influenced by radiative recombination, which is highly nonexponential. On the other hand, the relatively sharp drop of the $\mu$-PCD signals in the longer time region reflects the decreased bulk carrier lifetime at relatively low injection levels. It is obvious, by elevating temperature, the slope of this decay curve becomes small throughout the whole region measured in this study. This result arises partly from the increase in the emission rate of the carriers from the traps by elevat- ing temperature. ${ }^{16-18}$ On the other hand, the temperature change should influence the carrier diffusion inside the epilayers. With increasing temperature, the carrier diffusion is suppressed by enhanced phonon scattering. Thus, the influence of these surface, interface and substrate recombination may be reduced, which also leads to the increase in measured carrier lifetimes. ${ }^{19}$ The activation energy obtained from the Arrhenius plots of carrier lifetimes was very small, $0.1 \mathrm{eV}$ or less. At present, it is not clear what this activation energy means. From the shapes of the decay curves, however, it is confirmed that the slope of the fast decay at the initial stage, which is strongly influenced by the surface recombination, does not change remarkably. Thus, it can be speculated that the increase in carrier lifetimes with elevating temperature is mainly attributed to the increase in the emission rate of carriers from the traps.

Figure 4 shows the PCD curves measured for both epilayers after thermal oxidation process at the same location and the same excitation intensity as those in Fig. 3. Compared to the Fig. 3, it is obvious that the carrier lifetimes become longer, particularly for the n-type epilayer. This lifetime improvement can be attributed to the elimination of the $\mathrm{Z}_{1 / 2}$ centers by thermal oxidation process that was observed in n-type $4 \mathrm{H}-\mathrm{SiC}$ in our previous work. ${ }^{10}$

Figure 5 depicts the injection level dependencies of carrier lifetimes at RT and $250{ }^{\circ} \mathrm{C}$ for (a) p-type and (b) n-type $4 \mathrm{H}-\mathrm{SiC}$ epilayers before and after thermal oxidation. In both p-type and n-type epilayers, the carrier lifetimes gradually increase with increasing the injection level except for the very high-injection condition $\left(10^{16} \mathrm{~cm}^{-3}\right.$ ranges $)$. This gradual increase in the carrier lifetimes with increasing the injection level can be explained by a classical SRH model when the capture cross section for minority carriers is large enough compared to those for majorities ${ }^{16}$ and this result is consistent with a previous report. ${ }^{7}$ After thermal oxidation, the carrier lifetimes for both types of epilayers were improved in most of measured temperature range and injection levels. As a result, the carrier lifetime reaches $4.1 \mu \mathrm{s}$ in p-type and $6.1 \mu \mathrm{s}$ in n-type epilayers at $250{ }^{\circ} \mathrm{C}$ with an injection level of $1.8 \times 10^{16} \mathrm{~cm}^{-3}$. This lifetime improve- 


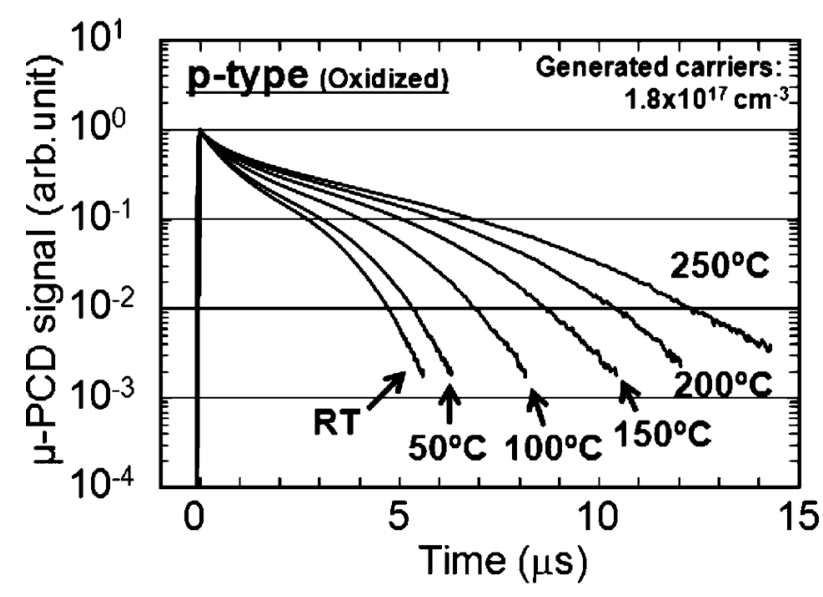

(a)

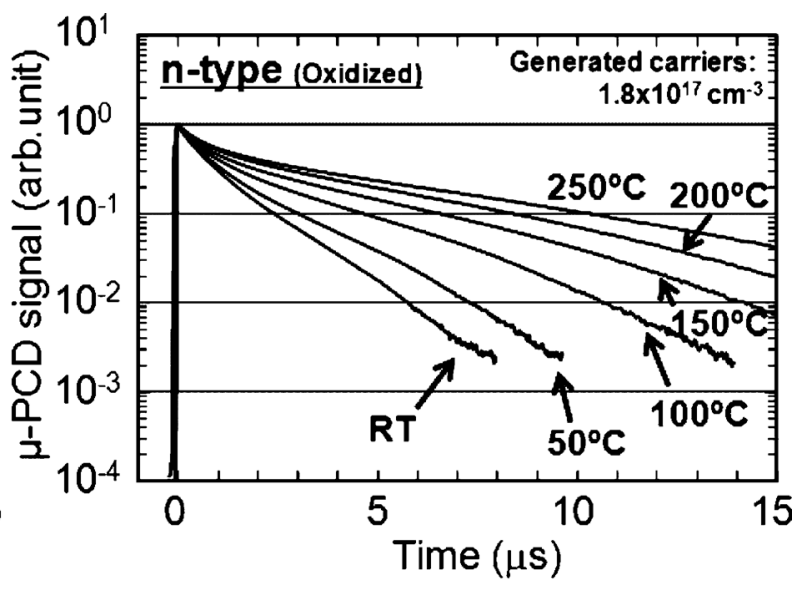

(b)

FIG. 4. PCD curves measured after thermal oxidation process for $50 \mu \mathrm{m}$ thick (a) p-type and (b) n-type epilayers at the same location as Fig. 3 at various temperatures. The excitation intensity is $1.8 \times 10^{17} \mathrm{~cm}^{-3}$.

ment can be attributed to the elimination of the $\mathrm{Z}_{1 / 2}$ center by thermal oxidation as mentioned above. However, the improvement for the p-type epilayer is not so much as the case of n-type. This difference is considered as follows. Here, two assumptions are made. Although no direct evidences have been given, it may be reasonable to assume that the $Z_{1 / 2}$ center also exists in p-type SiC. The charge state of the defect will be different because the Fermi level is different in between $\mathrm{p}$ - and $\mathrm{n}$-type $\mathrm{SiC}$. Another assumption is that the $\mathrm{Z}_{1 / 2}$ center in p-type $4 \mathrm{H}-\mathrm{SiC}$ may be also reduced by thermal oxidation. If the $Z_{1 / 2}$ center is a dominant lifetime killer in $4 \mathrm{H}-\mathrm{SiC}$ epilayers, the carrier lifetimes of p-type and n-type epilayers after the thermal oxidation would become comparable, at least, in the high-injection region according to the SRH model. However, a clear difference in carrier lifetimes is observed between p-type and n-type epilayers. In Fig. 6, the PCD curves at $250{ }^{\circ} \mathrm{C}$ for p-type and n-type epilayers after thermal oxidation are compared. From this figure, the carrier lifetime of the p-type epilayer becomes shorter than n-type especially in the low-injection region. In this case, according to the SRH model, this difference may originate from the difference of bulk lifetime. Thus, the benefit of the elimination of the $Z_{1 / 2}$ center by thermal oxidation may be cancelled by generating another deep level by the oxidation, such as the HK0 center. ${ }^{20}$ Though it should be confirmed whether the HK0 center acts as an effective lifetime killer of p-type material. While, even if the lifetimes are determined by the $Z_{1 / 2}$ center in both n-type and p-type epilayers, the difference in the observed lifetimes between these two materials may be expected from the fact that minority carriers in each material are trapped by the defect with different charge state and thereby different capture cross section. In addition, the influence of surface recombination and recombination in the substrate may still remain. ${ }^{21,22}$ For example, the oxidation process may affect the surface of p-type material differently than n-type material, so that enhanced surface recombination may occur in p-type material.

On the other hand, the lifetimes drop in the highinjection region for both p-type and n-type epilayers as shown in Fig. 5. Under the high-injection condition, the surface band bending may be flattened due to the increased concentration of excited carriers. ${ }^{23}$ This change in surface band structure will increase the surface recombination velocity and thereby enhance the fast decay at the initial stage.

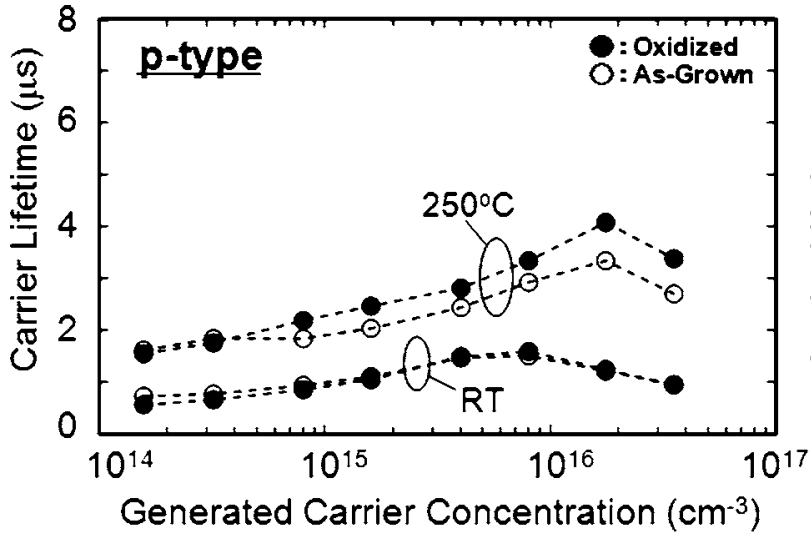

(a)

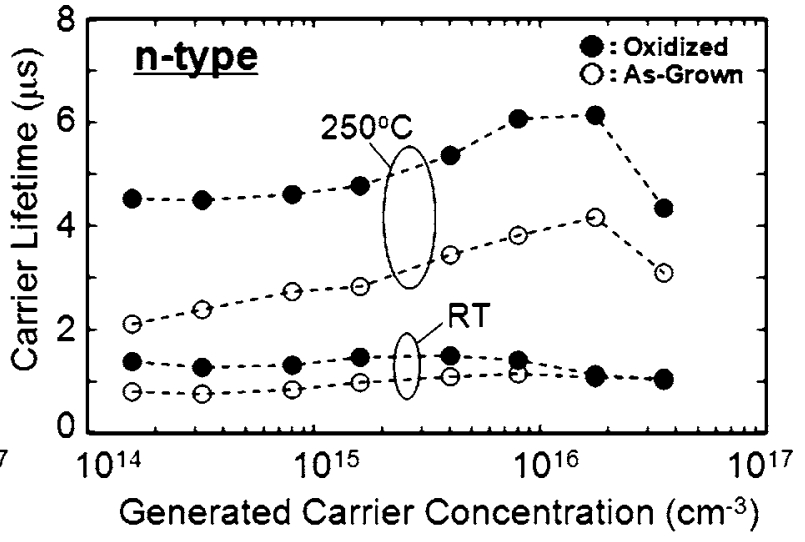

(b)

FIG. 5. Comparison of injection level dependencies of carrier lifetimes for $50 \mu \mathrm{m}$ thick (a) p-type and (b) n-type 4H-SiC epilayers before (as-grown) and after thermal oxidation. 


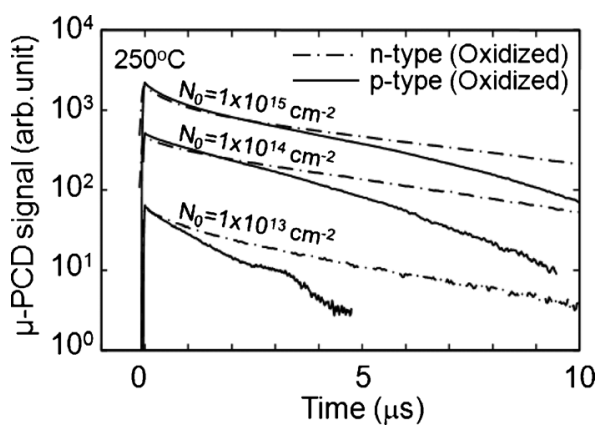

FIG. 6. Comparison of PCD curves of thermally oxidized p-type and n-type epilayers measured at $250{ }^{\circ} \mathrm{C}$ with various excitation intensities.

Another reason for the decreased lifetime in the highinjection region may be related to the carrier diffusion toward the substrate. By increasing the excitation intensity, the concentration of excited carriers just after the excitation pulse (the initial profile) increases while keeping the same exponential decay function determined by the absorption coefficient, as shown in Fig. 1. The absolute value of the concentration gradient toward the depth, however, also increases with increasing the excitation intensity, which may enhance the carrier diffusion toward the substrate and effectively reduce the measured carrier lifetimes.

\section{CONCLUSION}

We have investigated the temperature and injection level dependencies of carrier lifetimes in $50 \mu \mathrm{m}$ thick p-type and n-type $4 \mathrm{H}-\mathrm{SiC}$ epilayers by differential $\mu$-PCD measurements. In both p-type and n-type epilayers, the carrier lifetimes gradually increase with increasing the injection level except for the very high-injection levels. In the low-injection region, the gradual increase in the carrier lifetimes with increasing the injection level can be explained by a classical SRH model when the capture cross section for minority carriers is large enough compared to that for majorities. On the other hand, the decrease in carrier lifetime in the highinjection region may be ascribed to the influence of recombination in the substrate by the increase in the concentration gradient and to the enhanced surface recombination by flattening of band bending. The carrier lifetimes exhibited continuous increase with elevating the temperature for both epilayers. This increase in carrier lifetime at elevated temperature may be mainly caused by the increase in the emission rate of carriers from the traps. The impacts of thermal oxidation on the carrier lifetimes in both p-type and n-type epilayers have been also investigated. For both types of epilayers, especially for the n-type epilayer, the carrier lifetimes were remarkably improved by the thermal oxidation. At $250{ }^{\circ} \mathrm{C}$ and an injection level of $1.8 \times 10^{16} \mathrm{~cm}^{-3}$, the carrier lifetime reaches $4.1 \mu \mathrm{s}$ in the p-type and $6.1 \mu \mathrm{s}$ in the n-type epilayers.

${ }^{1}$ H. Matsunami and T. Kimoto, Mater. Sci. Eng. R. 20, 125 (1997).

${ }^{2}$ J. A. Cooper, Jr., M. R. Melloch, R. Singh, A. Agarwal, and J. W. Palmour, IEEE Trans. Electron Devices 49, 658 (2002).

${ }^{3}$ R. Rupp, M. Treu, S. Voss, F. Björk, and T. Reimann, Proceedings of the 18th International Symposium on Power Semiconductor Devices and ICs, Napoli, 2006, pp. 269-273.

${ }^{4}$ J. P. Bergman, O. Kordina, and E. Janzén, Phys. Status Solidi A 162, 65 (1997).

${ }^{5}$ T. Tawara, H. Tsuchida, S. Izumi, I. Kamata, and K. Izumi, Mater. Sci. Forum 457-460, 565 (2004).

${ }^{6}$ P. B. Klein, B. V. Shanabrook, S. W. Huh, A. Y. Polyakov, M. Skowronski, J. J. Sumakeris, and M. J. O'Loughlin, Appl. Phys. Lett. 88, 052110 (2006).

${ }^{7}$ K. Danno, D. Nakamura, and T. Kimoto, Appl. Phys. Lett. 90, 202109 (2007).

${ }^{8}$ S. A. Reshanov, W. Bartsch, B. Zippelius, and G. Pensl, Mater. Sci. Forum 615-617, 699 (2009)

${ }^{9}$ L. Storasta and H. Tsuchida, Appl. Phys. Lett. 90, 062116 (2007).

${ }^{10}$ T. Hiyoshi and T. Kimoto, Appl. Phys. Express 2, 041101 (2009).

${ }^{11}$ A. K. Agarwal, J. B. Casady, L. B. Rowland, S. Seshadri, R. R. Siergiej, W. F. Valek, and C. D. Brandt, IEEE Electron Device Lett. 18, 518 (1997).

${ }^{12}$ Q. Zhang, C. Jonas, B. Heath, M. Das, S. Ryu, A. Agarwal, and J. Palmour, Mater. Sci. Forum 556-557, 771 (2007).

${ }^{13}$ K. Schroder, Semiconductor Materials and Device Characterization, 3rd ed. (Wiley, New York, 2006), Chap. 7.

${ }^{14}$ S. G. Sridhara, T. J. Eperijesi, R. P. Devaty, and W. J. Choyke, Mater. Sci. Eng., B 61-62, 229 (1999).

${ }^{15}$ T. Kimoto, K. Danno, and J. Suda, Phys. Status Solidi B 245, 1327 (2008).

${ }^{16}$ W. Shockley and T. Read, Jr., Phys. Rev. 87, 835 (1952).

${ }^{17}$ P. B. Klein, J. Appl. Phys. 103, 033702 (2008).

${ }^{18}$ P. B. Klein, R. Myers-Ward, K.-K. Lew, B. L. VanMil, C. R. Eddy, Jr., D. K. Gaskill, A. Shrivastava, and T. S. Sudarshan, Mater. Sci. Forum 645648, 203 (2010).

${ }^{19}$ A. Galeckas, J. Linnros, M. Frischholz, and V. Grivickas, Appl. Phys. Lett. 79, 365 (2001).

${ }^{20}$ T. Hiyoshi and T. Kimoto, Appl. Phys. Express 2, 091101 (2009).

${ }^{21}$ P. B. Klein, R. Myers-Ward, K.-K. Lew, B. L. VanMil, C. R. Eddy, Jr., D. K. Gaskill, A. Shrivastava, and T. S. Sudarshan, J. Appl. Phys. 108, 033713 (2010).

${ }^{22}$ T. Kimoto, T. Hiyoshi, T. Hayashi, and J. Suda, J. Appl. Phys. 108, 083721 (2010).

${ }^{23}$ E. Yablonovitch, D. L. Allara, C. C. Chang, T. Gmitter, and T. B. Bright, Phys. Rev. Lett. 57, 249 (1986). 